\title{
Research on the Influence of Artistic Conception of Chinese Painting on Creative Image Design
}

\author{
Wei $\mathrm{Bi}^{1, a}$ and Zidong $\mathrm{He}^{2, \mathrm{~b}}$ \\ ${ }^{1}$ School of Art and Design, Guangdong University Of Finance \& Economics. Guangzhou 510000, \\ China \\ ${ }^{2}$ Guangzhou creative intelligent manufacturing Culture Communication Co., Ltd. Guangzhou 510000, \\ China \\ abeebvv@qq.com, b253279897@qq.com \\ *Wei Bi
}

\begin{abstract}
Keywords: Chinese paintings Artistic conception Creative image design.
\end{abstract}
\begin{abstract}
. with the development of global economy, the process of global integration is accelerating. With the deepening of regional and national exchanges and the development of cultural integration, the design language and design style are gradually internationalized. On the contrary, the country lost the unique cultural connotation and aesthetic characteristics of the design, and gradually tends to homogenization. At present, country pays attention to the re-localization of the design, especially the re-culture, re-value and re-art. As the Chinese quintessence, we should discuss the Chinese painting from its artistic conception in order to show its aesthetic characteristics again. At the same time, the artistic conception is the core of traditional aesthetics, which can determine our visual elements essentially and can be used in the creative graphic design to form a unique artistic conception figure. At last, the design could stand on the top of the world.
\end{abstract}

\section{Introduction}

With the changes of the times, the design has gradually entered to a new field. Visual art stands at the pinnacle of human design aesthetics, at the same time, culture is gradually changing to visual culture. Graphic design plays an important part in the visual culture, which creates a real situation closely related to life on levels and angles. Design is accompanied by us all the time in our life, which means the designs of almost all things that can be contacted by people are ubiquitous, especially the graphic design, such as billboards, advertisings, periodicals, newspapers, brand stores and so on. All the kinds of plane visual elements are influenced on our life and works. The graphics and symbols among the elements occupy an important position, which deeply affects our way of thinking and life. As a carrier that transcends culture and national boundaries, graphics play an inestimable role in the dissemination and development of economy and culture. There are two questions that need to be faced together by art inheritors of traditional Chinese painting and designers of visual arts in order to create creative graphic design with Chinese flavor, firstly, how to treat tradition, secondly, how to inherit and pass on the tradition of Chinese painting under the background of the social environment at present. Based on the background, the paper analyzes the artistic conception of Chinese painting and the development of creative graphic design, and discuss the way to inherit the traditional aesthetic way so that could create the graphic works belonging to the oriental flavor.

\section{Discussion on the Artistic Conception of Creative Graphics}

The concept of artistic conception originated from the aesthetics of Laozi and Zhuangzi. The essence of artistic conception is to integrate the subjective emotion of the author, combined the feeling and the situation. The artistic conception of Chinese painting, it means to display the poetry of the scene, which is the spiritual goal pursued by the painters. The traditional Chinese aesthetic way emphasizes the dual ideological connotation of spiritual pursuit and artistic conception. Artistic conception was used to express the spiritual charm of the pursuit of the world with the objective reflection and the 
subjective emotion of the painters. This artistic form can be reflected in painting, sculpture, architecture and so on. At the same time, as one of the important elements of modern graphic design, creative graphic design can more reflect the sense of vision brought by the artistic conception of Chinese painting. It is true that the essence and treatment of creative graphic design and painting art are not exactly the same, but as cultural aesthetic symbols, the relationship between artistic conception and image should be considered. Therefore, as a new artistic concept and design thinking of modern creative graphic design, graphic context theory is the result of people placing the artistic conception theory of Chinese painting in modern creative graphic design, which is helpful to the innovation and development of design works.

There are several rules of graphic artistic conception including "Combined with desire and image", "Blended of feeling and setting" and " Combined with virtual and real". " Combined with conception and image " mainly refers to the relationship between artistic conception and image, they are not only opposed to each other but also are interdependent. In creative graphic design, graphics are the carrier of artistic conception, and artistic conception carries the spiritual content of graphics. Blended of emotion and scene is further deepened on the basis of the combination with desire and image, mainly refers to the creation of "emotion" and "scene" is in line with the internal relevance of an artistic way. The embodiment of specific "emotion" needs to be attached to the special visual "scene". The designer should grasp the internal relationship between emotion and scenery, in order to convey the contents that the authors want to express through the actual graphics. The combination of virtual and real mainly expounds the layout requirements of graphics. In the graph, it mainly reflects the artistic feeling that a fewer can often defeat more. Through the abandonment of some specific forms to highlight the essential characteristics of the subject.

\section{The Innovation of the Creative Graphics of the Artistic Conception}

Creative graphic design is not only an innovation, but also a way of thinking and cultural consciousness. In order to combine artistic conception with graphics, we should find out the starting point of traditional culture and modern concept to create excellent visual effect. The creation of artistic conception graphics should be discussed from the point of view of creative thinking.

The first is the innovation of thinking, and the most important way is to obtain artistic conception through association, to expand thinking through this way of change, to enlighten the understanding of things, and to obtain the final inspiration. If the special picture features of Chinese painting are combined with modern graphics, then association is an indispensable means. With the help of the association of thinking, the tradition and the modern can be skillfully combined, which means to take irrelevant things into the two- levels and one-form on the cognitive angle and understanding through the association, so as to achieve the purpose of creative results.

This kind of association can absorb and utilize the artistic conception content of Chinese painting through the derivation of form, the correlation of connotation, the innovation of technique and the reconstruction of graphics, as well as the charm of Chinese painting. Taking the logo of 2008 Chinese Olympic for instance。 the overall style does not directly refer to or borrow the traditional modeling, but consciously uses the freehand brushwork between yes and no to convey the symbolic image of "Chinese knot" and "athlete", which reflects the harmony and stability of the cultural interior. This kind of Chinese unique aesthetic artistic conception and philosophical thinking conveys the essence concept of "Chinese charm". Although it does not directly reflect the charm of Chinese painting, the image meaning conveyed by connotation is more vivid.

\section{Summary}

The original intention of the design is to be used by people, and the national characteristics that come from the regional nature make the design full of national character. Therefore, the graphics with national characteristics is the design with re-value. As long as you give full play to the artistic conception and charm of Chinese design, you can have some unique practices on the design. The paper explores the enlightenment and influence of artistic conception on Chinese painting based on 
the visual and spiritual of Chinese painting. Besides, by the analysis, discuss how to integrate the artistic conception of Chinese painting into the graphic creativity in order to make the design have more national flavor and influence on more countries by the charm of Chinese design and Chinese painting.

\section{References}

[1] He Hui,Bright and Glossy, Good-mannered and Powerful- On the occasion of the opening of the "Extraordinary" exhibition, Chinese Painting,2011(06).

[2] Pang Peibei, The relationship between "drawing" and "background" in art design, Journal of Xinyang Agricultural College,2007(02).

[3] Zheng Lu, On the Application of Graphic, Text and Color in Graphic Design , Journal of Jilin Teachers Institute of Engineering and Technology,2006(10).

[4] Yang $\mathrm{Xu}$, The Application of Guangxi Minority brocade pattern in Modern graphic Design ,Art and design (theory), 2008(06).

[5] Jia Yuqian, A Brief Analysis of the Application of the Figure-bottom Reverse Graphics of "Being and Not being grow out of one another" in the Plane Field, Popular Literature,2010(24).

[6] Zhan Chunyu, On the Application of figure in graphic Design,New technology and new products of China,2009(03). 